\title{
L tipi köşe birleştirmelerinde epoksi reçinesinin eğilme moment üzerine etkisi
}

\section{Effect of epoxy resin on bending momentum in L type corner joins}

\author{
Mehmet Nuri YILDIRIM', Abdurrahman KARAMAN², Recep AYKAN ${ }^{3}$, Hüseyin YEŞiL ${ }^{4}$ \\ ${ }^{1}$ Karabük Üniversitesi, Safranbolu MYO, Malzeme ve Malzeme İşleme Teknolojileri Bölümü, Karabük, Türkiye \\ ${ }^{2}$ Uşak Üniversitesi, Banaz MYO, Ormancılık Bölümü, Uşak, Türkiye \\ ${ }^{3}$ Artvin Çoruh Üniversitesi, Artvin MYO, Malzeme ve Malzeme İşleme Teknolojileri Bölümü, Artvin, Türkiye \\ ${ }^{4}$ Dumlupınar Üniversitesi Simav Teknoloji Fakültesi Ağaç İşleri Endüstri Mühendisliği Bölümü, Kütahya, Türkiye
}

Eser Bilgisi / Article Info
Araştırma makalesi / Research article
DOI: 10.17474/artvinofd.307974
Sorumlu yazar / Corresponding author
Mehmet Nuri YILDIRIM
e-mail: mnyildirim@karabuk.edu.tr
ORCID: 0000-0002-0180-4479
Geliş tarihi / Received
23.04.2017
Düzeltme tarihi / Received in revised form
07.10.2017
Elektronik erişim / Online available
31.10.2017
Anahtar kelimeler:
Köşe birleştirme
Epoksi
Ahşap bisküvi
Eğilme momenti
Keywords:
Corner joint
Wood biscuit
Epoxy
Bending moment

\begin{abstract}
Özet
Mobilya endüstrisinde, çerçeve ve kutu konstrüksiyonlu mobilyaların birleştirme noktalarının kullanım yeri etkisinde kalacak yüklere göre tasarlanması kullanıcının güvenliği ve mobilya elemanın servis ömrü açısında önem arz etmektedir. Bu önemden yola çıkarak, masif ahşap malzemelerden hazırlanan kutu konstrüksiyonlu mobilyaların " $\mathrm{L}$ " tipi köşe birleştirmelerinin diyagonal basma ve diyagonal çekme eğilme moment değerlerinin belirlenmesi amaçlanmıştır. Bu amaca ulaşmak için Karaçam (Pinus Nigra), Doğu Kayın'ı (Fagus Orientalis L.) ve Kavak (Populus Nigra) masif ahşap malzemelerden kutu tipi konstrüksiyonlar oluşturulmuştur. Deney konstrüksiyonun köşe birleştirmelerinde odun esaslı bisküvi birleştirme elemanı ve yapıştırıcı olarak epoksi reçinesi kullanılmıştır. Deney ASTM-D1037 esaslarına göre statik yükleme uygulanmıştır. Deney sonuçlarına göre; çekme ve basma deneylerinde en yüksek eğilme moment değeri Doğu kayını örneklerinde, en düşük değerin ise Kavak örneklerinde olduğu belirlenmiştir. Araştırmada çekme eğilme momenti değerleri basma eğilme momenti değerlerinden yüksek çıkmıştır. Yapılan istatistik çalışmasında, bisküvi birleştirme elemanının çekme ve basma eğilme moment değerleri arasındaki farklılık istatistiksel olarak anlamlı bulunmuştur. Araştırmanın sonuçları doğrultusunda, Epoksi reçinesi ve odun esaslı bisküvi birleştirme elemanı kullanarak Doğu Kayınından hazırlanan L tipi birleştirmelerin çerçeve kontstrüksiyonlarda kullanımı önerilebilir.
\end{abstract}

\begin{abstract}
In the furniture industry, the joining points of frame and box construction furniture according to the loads to be affected by the use place is important for the security of the user and service life of the furniture element. In this direction, it is aimed to determine the diagonal compression and diagonal tensile moment values of "L" type corner joints of box framed construction furniture prepared from solid wood materials. The Pinus Nigra, Fagus Orientalis $L$ and Populus Nigra were used as solid wood materials. Wood-based biscuit joining elements were used in corner joints of the test construction and epoxy resin was used as glue for materials. The static loads were applied to construction according to ASTM-D1037. The results show that, the highest tensile and compression values were obtained from Fagus Orientalis $L$ and the lowest values were obtained from Populus Nigra specimens. In the statistical study, the difference between the tensile and compressive bending moment values of the biscuit connection element was found to be statistically significant. This study indicates that, it is suggested to use of $L$ type joints prepared from Fagus Orientalis $L$ by using epoxy resin and wood based biscuit joining element in frame constructions.
\end{abstract}

\section{Giriş}

Ahşap ve ahşap esaslı malzemeler, mobilya olgusunun, dolayısı ile mobilya konstrüksiyon tasarımının önemli bir bileşenini oluşturmaktadır. Mobilya ürününün oluşumunda yer alan ahşap ve ahşap esaslı malzemeler olan Karaçam, Doğu kayını ve Kavağın, fiziksel ve mekanik etkilere karşı davranış biçimlerinin önceden bilinmesi, tasarımcı, üretici ve kullanıcılara teknik, estetik ve ekonomik yararları açısından büyük önem taşımaktadır (Efe 1994).

Ahşap ve ahşap esaslı malzemelerin birleşiminde kullanım yeri ve amacına göre yapıştırıcılar kullanılmaktadır. Bunlardan bir tanesi de kullanım alanı oldukça geniş olan epoksi reçinesidir. Epoksi reçinesi, mekanik dayanımı ve kimyasal yapısından dolayı mühendislikte artan oranda kullanılan bir yapıştırıcı türüdür (Swamy ve ark. 1987). Nitekim Steiger (2003) yaptığı çalışmada, ahşap yapılarda 
yüksek performanslı karbon fiber takviyeli polimerlerin epoksi ile ahşaba yapıştırılması ve kullanılan epoksinin çekme dayanımına etkisi üzerine çalışmalar yapmıştır. Optimum sıcaklıkta en iyi güçlendirme özelliklerini tespit etmiştir. Yapılan deneysel çalışmalar sonucunda CFRP ile Epoksi reçinesinin ahşaba yapışma sıcaklı̆̆ının optimum değerlerinin tutkal üreticilerinin verdiği değerler ile uyumlu olduğunu ifade etmiştir. Yazar, beton kirişlerin güçlendirilmesinde yeni bir kompozit olan mineral tabanlı kompozit (MBC) kullanmış ve CFRP ile yapılan güçlendirilmelerle karşılaştırmıştır. Benzer bir çalışma Taljsten and Blanksvard (2007) tarafından yapılmıştır. Söz konusu çalışmada, yapıştırıcı olarak Epoksinin betonla birleşerek dayanıklı bir bütün oluşturduğunu ortaya koymuşlardır. Yapılan bu çalışmalardan hareketle, araştırmada epoksi reçinesinin kullanılmasının nedeni, ahşap ve ahşap esaslı malzemelerin birleşmesinde göstereceği performansı belirlemektir.

Karaman ve ark. (2017) yaptığı araştırmada, epoksi tutkalı ile yapıştırılan deney örneklerinin, diyagonal kuvvet taşıma kapasitesi en yüksek değer gösterdiğini ve bu bağlamda, $L$ tipi köşe birleştirmelerinde yüksek dayanım gösteren epoksi tutkalının kullanılması önermişlerdir.

Ahşap ve ahşap esaslı malzemelerde, nem, yüzey düzgünlüğü, odun türü, tutkal tipi ve tutkalın kimyasal özelliği ahşap konstrüksiyonlarının dayanıklılığı üzerine tutkallama koşullarına uygun değişim gösterdiği bilinmektedir (Kaya 1977). Nitekim Smardzevski (2002), ahşap mobilya ve yapı elemanlarının birleşme yerlerindeki eğilme, açılma veya kırılma gibi deformasyonların genellikle tutkallama işlemlerinde meydana gelen teknolojik hatalardan kaynaklandığını belirtmiştir. Rowell (2005) yaptığı araştırmada, ağaç malzemenin türü, yüzey düzgünlüğü ve yoğunluğu gibi özelliklerin ayrıca yapıştırıcı olarak kullanılan tutkalın viskozitesi, pH oranı, yüzey penetrasyonu, molekül ağırlığı, içindeki katı madde miktarı ve tutkallama şekli gibi özelliklerin de yapışmayı etkilediğini tespit etmiştir.

Konstrüksiyon birleştirmelerinde geleneksel ve modern birleştirme tipleri uygulanmaktadır. Geleneksel birleştirmelerden biri $L$ tipi birleştirme türüdür. $L$ tipi birleştirmeler özellikle çerçeve konstrüksiyonlarda uygulanmaktadır. Bu birleştirme tipi kullanım yerinde eğilme, çekme ve basma yüklerine maruz kalmaktadır. Nitekim literatür incelendiğinde, (Atar ve ark. 2006; Çelikel 2006; Vassiliou ve Barboutis 2006; Türk 2007; Demirel 2008; Tüfekli 2010; Yüce 2016; Aslan 2006; Efe ve ark. 2006; Kasal ve ark. 2007; İmirzi 2008; Danacı 2009; Ekrem 2010; Tüfekli 2010; Çağatay 2011; Efe ve ark. 2012; Efe ve ark. 2014) L tipi köşe birleştirmelerin mukavemeti ile ilgili yapılan çalışmaların benzer sonuçlar ortaya koyduğu söylenebilir.

Karaman ve ark (2017) yaptıkları araştırmada, epoksi tutkalının daha yüksek performans göstermesinin nedeni daha elastik olması böylece moleküler düzeyde ahşap bisküvi yüzeyine ve bisküvi deliği yüzeylerine yapışma yüzey boşluklarına diğer yapıştırıcılara göre daha fazla ve hızla nüfus ederek, bu bölgelerde tutkal ve malzeme moleküllerinin daha kuvvetli özellikli mekanik adezyon kuvveti kurması neticesinde kuvvetli bir yapışma yüzeyi oluşturmasından kaynaklandığı bildirmişlerdir.

Mobilya endüstrisinde, çerçeve ve kutu tipi mobilya konstrüksiyonların köşe birleştirmesinde konstrüksiyonun moment taşıma kapasitesi; kullanılan masif ahşap malzemenin türüne, birleştirme elemanına ve birleştirmede kullanılan tutkalla bağlıdır. Mobilya elemanlarının köşe birleştirmelerinde farkı bağlantı elemanı ve tutkal çeşitleri kullanılmaktadır. Bu araştırmada ise, odun esaslı bisküvi birleştirme elamanı ve epoksi reçinesi ile birleştirilen karaçam, doğu kayını ve kavak masif ahşap malzemelerden hazırlanan $L$ tipi köşe birleştirmelerinin basma ve çekme eğilme momenti değerlerinin belirlenmesi amaçlanmıştır.

\section{MATERYAL ve YÖNTEM}

Bu çalışmada, mobilya endüstrisinde yaygın kullanılan Karaçam (Pinus Nigra), Doğu kayını (Fagus Orientalis L.) ve Kavak (Populus Nigra) ahşap masif malzemeler kullanılmıştır. Araştırmada kullanılan keresteler, Karabük Yenice ilçesindeki kereste işletmelerinden rastgele yöntemle tedarik edilmiştir. Kerestelerin seçiminde; ardaksız, sağlam, budaksız, düzgün lifli, kuru, mantar ve böcekler tarafından zarar görmemiş olmasına özen gösterilmiştir. Deneylerde kullanılan ahşap malzemelerin bazı fiziksel ve mekanik özellikleri Çizelge 1 'de verilmiştir. 
Çizelge 1 Ahşap malzemelerin bazı fiziksel $(\%),\left(\mathrm{gr} / \mathrm{cm}^{3}\right)$, ve mekanik özellikleri $\left(\mathrm{N} / \mathrm{mm}^{2}\right)$

\begin{tabular}{lllll}
\hline Malzeme & Rutubet & Yoğunluk & E.Gerilmesi & E. Modülü \\
\hline Karaçam (Pinus Nigra) & 8.7 & 0.56 & 119.9 & 7061 \\
Doğu Kayını (Fagus Orien. L.) & 8.5 & 0.65 & 122.9 & 12462 \\
Kavak (Populus Nigra) & 8.8 & 0.43 & 65 & 8800 \\
\hline
\end{tabular}

Not: E. Gerilmesi= Eğilme Gerilmesi, E. Modülü = Elastikiyet Modülü

Ahşap bisküvi lamellere üretim aşamasında preslenerek açılan diyagonal kanallar, tutkalın bisküvi lameller yüzeyine homojen olarak dağıımasını sağlamaktadır. Ayrıca levhaların presli olması, bisküvi lameller tutkalın rutubetiyle şişmesini sağlayarak parça içinde sıkı bir konum almasını sağlamaktadır (Çelikel 2006). Bisküvi lameller farklı ölçülerde bulunmakta ve farklı numaralarda adlandırılmaktadır. En çok kullanılan Bisküvi lameller: 20 numara ( $56 \times 23 \times 4 \mathrm{~mm}$ ), 10 numara ( $53 \times 19$ x $4 \mathrm{~mm}), 0$ numara $(47 \times 15 \times 4 \mathrm{~mm})$ olarak üretilmektedirler (Verbindugs 2005).

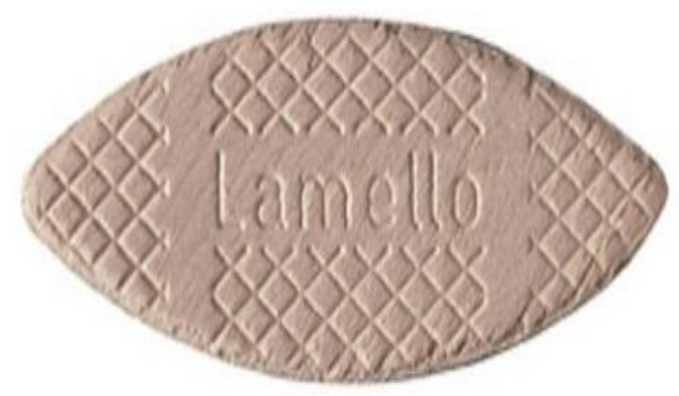

Şekil 1 Ahşap bisküvi (Verbindugs 2005).

Epoksi reçine tutkalı, kimyasal maddelere karşı dirençli, beton, çelik, ahşap ve plastik malzemelere mükemmel yapışma sağlamaktadır. Bu çalışma kapsamında kullanılan Epoksi reçinesinin; Yoğunluğu $1.18 \mathrm{~g} / \mathrm{cm}^{3}$ ve Viskozite 600-900 mPas'tır (Anonim 2016).

Bu çalışmada, malzeme olarak; mobilya endüstrisinde yaygın olarak kullanılan Karaçam (Pinus Nigra), Doğu kayını (Fagus Orientalis L.) ve Kavak (Populus Nigra) ahşap masif malzemeleri, birleştirme elemanı olarak 20 numaralı doğu kayınından yapılmış ahşap bisküvi ve epoksi reçinesi kullanılmıştır. Toplamda $(3 \times 2 \times 10) 60$ adet deney numunesi hazırlanmıştır. Karaçam (Pinus Nigra), Doğu kayını (Fagus Orientalis L.) ve Kavak (Populus Nigra) masif malzemelerden hazırlanan deney örneklerinden A elemanı; 132×100×18mm, B elemanı; 150x100x18mm ölçülerinde hazırlanmıştır (Şekil 2).

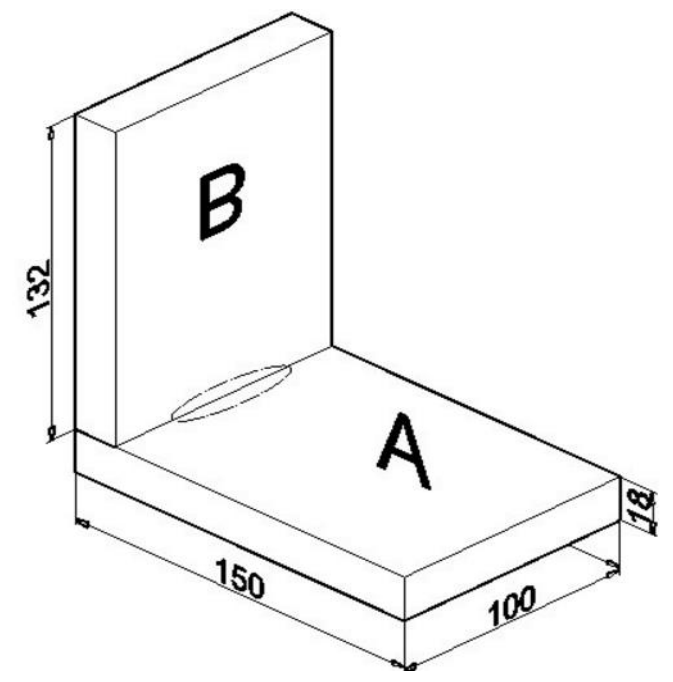

Şekil 2 Deney örneği (A elemanı, B elemanı, Ahşap bisküvi)

A gurubu elamanının cumba merkezine $50 \mathrm{~mm}$ içeride, parça kalınlığının ortasından geçecek şekilde $4 \mathrm{~mm}$ kalınlığında, $56 \mathrm{~mm}$ genişliğinde, $12 \pm 1 \mathrm{~mm}$ derinlikte, B grubu elemanın yüzeyine ise cumba merkezinden $50 \mathrm{~mm}$, maktadan yüzeye merkezi $9 \mathrm{~mm}$ içeride, $4 \mathrm{~mm}$ kalınlığında, $56 \mathrm{~mm}$ genişliğindedir. Ayrıca $12 \pm 1 \mathrm{~mm}$ derinlikte ve $12 \mathrm{~mm}$ derinliğinde ahşap bisküvinin geçeceği bisküvi deliği açılmıştır.
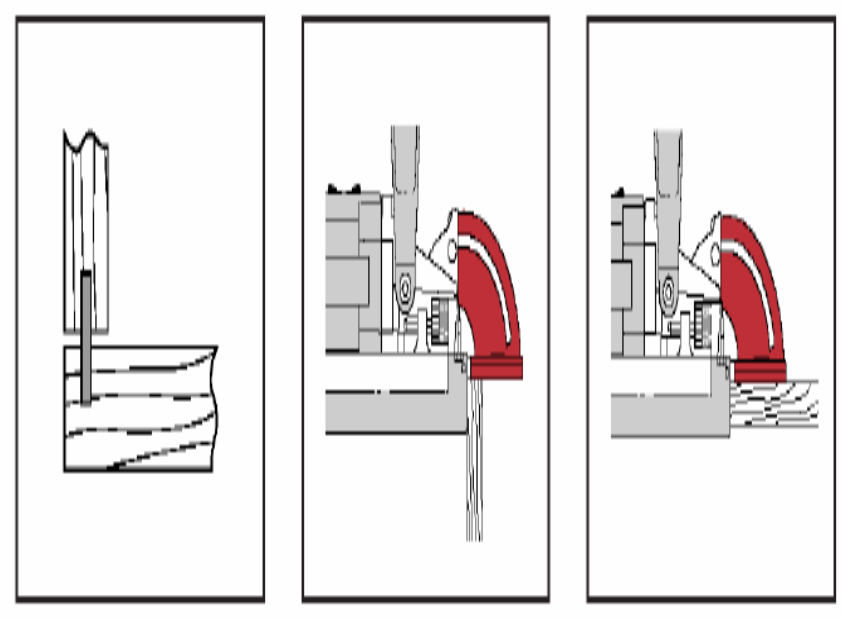

Şekil 3 Delik makinesinin konumu (Verbindugs 2005). 
Deney örneği hazırlanırken bisküvi delik makinesinin konumu Şekil 3'te gösterildiği gibi konumlandırılmıştır. Tutkallama işleminde, üretici firma öneri doğrultusunda $A$ grubu numunelerin yüzeylerine, B grubu numunelerin cumbalarına, ahşap bisküvi yüzeylerine ve bisküvi delik yüzeylerine ortalama $180 \pm 10 \mathrm{~g} / \mathrm{m}^{2}$ tutkal sürülmüştür. Deney örnekleri $0.2 \mathrm{~N} / \mathrm{mm}^{2}$ basınç altında soğuk preslenmiştir. Montajları yapılan örnekler $20 \pm 2{ }^{\circ} \mathrm{C}$ ve $\%$ $65 \pm 5$ bağıl nem şartlarında ağırlığı değişmez hale gelinceye kadar bekletilmiştir.

\section{YÖNTEM}

Deneyler 100 KN(kilo newton) yük kapasiteli üniversal test cihazında çekme ve basma hızı $10 \mathrm{~mm} /$ dak ve $20 \pm 2$ ${ }^{\circ} \mathrm{C}$ sıcaklığında statik yüklemeler uygulanmıştır. Moment kolları dik üçgen bağlantısından yararlanılarak çekme için $\mathrm{Lç}=0.08061 \mathrm{~m}$, basma için $\mathrm{Lb}=0.0933 \mathrm{~m}$ olarak hesaplanmıştır. Birleştirmelerin performansı, deney yükleri ve koşulları altında taşınan momentler olarak alınmış ve her bir örnek tarafından diyagonal çekme ve basma yükleri altında taşınan momentler hesaplanmıştır. Diyagonal çekme deneyinde yükleme şekli ve deney düzeneği Şekil 4'te, Diyagonal basınç deneyinde yükleme şekli ve deney düzeneği Şekil 5'te gösterilmiştir.

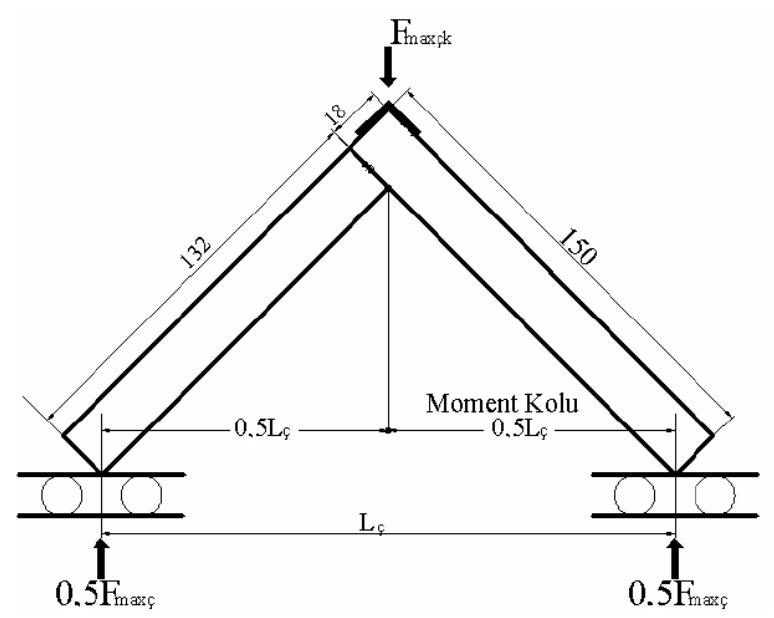

Şekil 4 Diyagonal çekme deneyi düzeneği $(\mathrm{mm})$.

Diyagonal çekme deneylerinde Moment (Mç) aşağıdaki formül ile hesaplanmıştır.

$M c ̧=0.5 F_{\text {maxçk }} \times 0.5 \mathrm{Lç}(\mathrm{N} . \mathrm{m})$

Burada; Mç= Moment (N.m), $F_{\max }=$ Maks. kuvvet (N), Lç= Moment kolu (80.61 mm ).

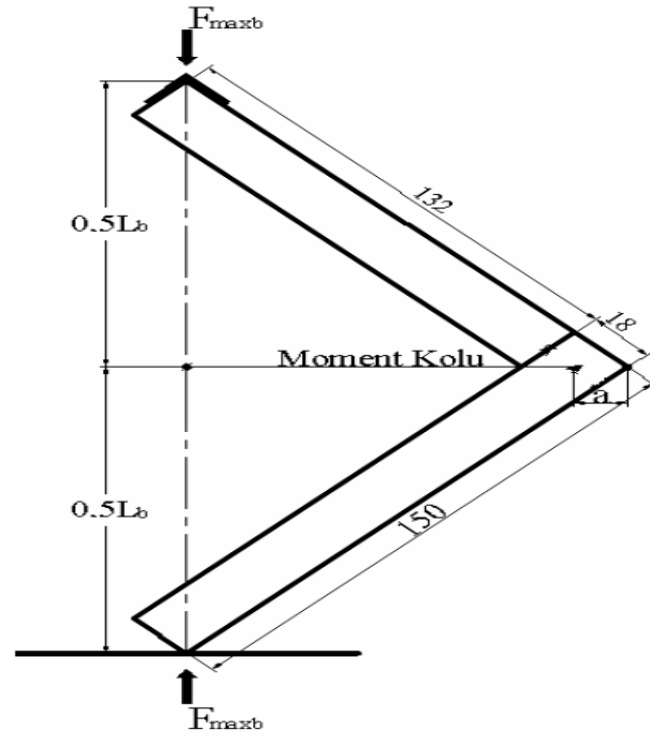

Şekil 5 Diyagonal basınç deneyi düzeneği $(\mathrm{mm})$

Diyagonal basınç deneylerinde moment (Mç), aşağıdaki formül ile hesaplanmıştır.

$M_{b}=F_{\operatorname{maxb}} \times\left[V(150)^{2}-(0,5 \mathrm{Lb})^{2}-a\right](N m)$

Burada; $F_{\max }=$ Maks. kuvvet, $M_{b}=$ Basınç kuvveti altında taşınan moment (N.mm),

$F_{\text {maxb }}=$ maksimum kuvvet $(N), L_{b}=$ Moment kolu (93.34 $\mathrm{mm}$ ) a= $12.73 \mathrm{~mm}^{\prime}$ dir

Deneylerde kullanılan ağaç türlerinin eğilme momenti üzerine etkisini belirlemek için çoklu varyans analizi (MANOVA) uygulanmıştır (\%95 güven aralığında). Gruplar arasındaki anlamlı bir farklılığın olup olmadığını belirlemek için ise duncan testi ile araştırmanın amacına ulaşılmaya çalışılmıştır.

\section{BULGULAR}

L tipi deney örneklerinin diyagonal çekme ve basınç deneyleri sonucu elde edilen eğilme moment istatistikleri Çizelge 2'de, bunlara ilişkin çoklu varyans analizi sonuçları ise Çizelge 3 'de verilmiştir. Çizelge 3 incelendiğinde, $L$ tipi köşe birleştirmelerinde ağaç türüne ilişkin ortalama çekme ve basma eğilme moment değerlerinin sırası ile Doğu Kayın'ında yüksek seviyede (51.07 N.mm, 45.97 N.mm), Kavak'ta ise (27.83 N.mm, 21.59 N.mm) düşük olduğu tespit edilmiştir. 
Çizelge 2 Çekme ve basma eğilme momentine ilişkin istatistiksel veriler( $\mathrm{Nmm})$.

\begin{tabular}{lllllllll}
\hline Ağaç Türü & \multicolumn{9}{l}{ Diyagonal Çekme } & \multicolumn{9}{l}{ Diyagonal Basma } \\
\cline { 2 - 9 } & Max. & Min. & A.O & S & Max. & Min. & A.O & S \\
Doğu Kayını & 52.28 & 49.86 & 51.07 & 1.79 & 47.18 & 44.76 & 45.97 & 1.72 \\
Karaçam & 37.50 & 35.08 & 36.29 & 2.72 & 32.13 & 29.71 & 30.92 & 1.07 \\
Kavak & 29.04 & 26.62 & 27.83 & 2.43 & 22.80 & 20.40 & 21.59 \\
\hline
\end{tabular}

Not: $A . O=$ Aritmetik Ortalama, S: Standart Sapma, Max= Maksimum, Min=Minimum

Çizelge 3 Çekme ve basma eğilme momentine ilişkin çoklu varyans analizi

\begin{tabular}{llllll}
\hline Kaynak & S.D & K. T. & K. O & F Değeri & P<\%5 \\
\hline Ağaç Türü (A) & 2 & 3387949.864 & 1693974.932 & 179.070 & 0.000 \\
Deney Metodu (B) & 2 & 230922.235 & 115461.118 & 12.205 & 0.000 \\
Etkileşim A×B & 4 & 751010,555 & 187752.639 & 19.847 & 0.000 \\
Hata & 81 & 766246.43 & 9459.833 & & \\
Toplam & 90 & 28385589.272 & & & \\
\hline
\end{tabular}

Not: $\mathrm{S}$. D= Serbestlik Derecesi, K. T= Karelerin Toplamı, K. O= Karelerin Ortalaması.

Ağaç türü $(A)$, deney metodu $(B)$ ve ikili etkileşimlerin $(A \times B)$ eğilme momenti üzerindeki etkileri 0,05 yanılma olasılığı için istatistiksel anlamda anlamlı bulunmuştur. Hesaplanan F değerlerine bakıldığında, eğilme moment değerinin en fazla Doğu Kayın'ından, daha sonra Karaçam'da, en az ise Kavak odunundan etkilendiği saptanmıştır. Anlamlı ilişki çıkan tüm değişkenlerin grup içeresinde birbirlerine karşı en küçük önemli farklarını belirlemek üzere yapılan duncan testi karşıllaştırma sonuçları, ağaç türüne göre Çizelge 4 'te ve deney metoduna göre ise Çizelge 5'te verilmiştir.

Çizelge 4 Ağaç türüne göre duncan testi sonuçları.

\begin{tabular}{lll}
\hline Ağaç Türü & N.mm & HG \\
\hline Doğu Kayını (Fagus Orientalis L.) & 48.52 & A \\
Karaçam (Pinus Nigra) & 33.61 & B \\
Kavak (Populus Nigra) & 24.71 & C \\
\hline
\end{tabular}

Çizelge 4 incelendiğinde ağaç türlerinden eğilme moment değerleri arasındaki fark önemli olup, en yüksek eğilme moment değeri sırasıyla Doğu Kayını (48.52 N.mm), Karaçam (33.61 N.mm) ve Kavak (Populus nigra) (24.71 N.mm) örneklerinde olduğu tespit edilmiştir.

Çizelge 5 Deney metoduna göre duncan testi sonuçları.

\begin{tabular}{lll}
\hline Deney Metodu & N.mm & HG \\
\hline Diyagonal Çekme & 38.40 & $\mathrm{~A}$ \\
Diyagonal Basınç & 32.83 & $\mathrm{~A}$ \\
\hline
\end{tabular}

Çizelge 5'e göre çekme'de eğilme momenti deneyi sonucu elde edilen eğilme moment değeri 38.40 N.mm, basma'da eğilme momenti deneyleri sonucu elde edilen eğilme moment değeri ise $32.83 \mathrm{~N} . \mathrm{mm}$ olarak belirlenmiştir.

\section{SONUÇ VE TARTIŞMA}

Bu çalışmada Karaçam, Doğu Kayını ve Kavak masif ahşap malzemeleri ile epoksi reçinesi ve bisküvi birleştirme elemanı kullanılarak hazırlanan L tipi köşe birleştirmelerin diyagonal çekme ve basma deneyleri sonucu elde edilen eğilme moment değerleri araştırılmıştır.

Araştırmada diyagonal çekme ve basma yüklemeleri altında taşınan ortalama eğilme moment değeri sırasıyla Doğu Kayını, Karaçam ve Kavak masif malzemelerinde olduğu belirlenmiştir. Araştırmada yapışma direnci ile yoğunluk arasında orantılı bir ilişki olduğu saptanmıştır. Yoğunluğun fazla olması, iç yüzey alanının büyümesine, dolayısıyla moleküllerin birbirine daha yakın konumlanarak adezyon kuvvetinin artmasına sebep olmaktadır. Dolayısıyla, Kayın odununun halkalı dağınık traheli, homojen yapısı, elastikiyet değerinin yüksek olması ve kesicilerle işlem gördükten sonra diğer ağaçlara göre daha düzgün ve pürüzsüz bir yüzey vermesi, yoğunluğun fazla olması birbirine temas eden yüzey alanının büyümesine neden olmaktadır. Keza yapışmaya katılan molekül miktarının fazlalığına, yani moleküllerin birbirine daha fazla adezyon kuvveti oluşturarak yapışmasına sebep olduğu söylenebilir.

Deney metodu duncan testi karşılaştırılmalarında, diyagonal çekme eğilme moment değerleri diyagonal basma eğilme moment değerlerinden \%17 daha fazla olduğu belirlenmiştir. Bu fark çekme deneyi sırasında deney örneğine uygulanan kuvvetin iki mesnet noktası ile 
karşılanmasından kaynaklanmakta olduğu düşünülmektedir. Araştırmada elde edilen bu sonucun, (Aslan 2006; Efe ve ark. 2006; Kasal ve ark. 2007; İmirzi 2008; Danacı 2009; Ekrem 2010; Taş, 2010; Tüfekli 2010; Çağatay 2011; Efe ve ark. 2012; Efe ve ark. 2014) yapılan bu çalışmaların sonuçları ile paralellik gösterdiği söylenebilir.

Bu çalışmada elde edilen sonuçlar, Karaçam, Doğu Kayını ve Kavak masif ahşap malzemelerinin bisküvi birleştirme elemanı aracılığıyla mobilya elemanları (koltuk, masa, dolap vb) üretiminde kullanılabileceğini göstermiştir. Bu çalışmada elde edilen değerlerin mobilya endüstrisinde üretim yapan üreticilere referans olacağı düşülmektedir. Yapıştırıcı kullanılarak elde edilen L tipi birleştirmelerde; birleştirmenin kullanım yerinde etkisinde kalacağı yüklemelere karşı performansını artırmak amacıyla yapıştırıcı ara yüzey bölgesine dayanım özellikleri geliştirilmiş karbon fiber takviyeli kompozit malzemelerin kullanımı ile ilgili çalışmanın yapılması ilgili literatüre zenginlik kazandıracağı düşünülmektedir.

\section{KAYNAKLAR}

Anonim (1996) Polisan ürün dökümantasyonu, Kocaeli

Anonim (2014) Orgalok marine ürün bilgi formu 1/11, Organik Kimya San. Tic. A.Ş

Anonim (2016) Dostimya ürün katoloğu, İstanbul.

Altınok M, Taş HH (2009) Melamin ile kaplanmış yonga levhalı (YL-lam) kutu mobilyalarda köşe birleştirmelerin yük taşıma kapasitesi. Süleyman Demirel Üniversitesi Fen Bilimleri Enstitü Dergisi, 13(3):305-310.

Altınok M (2003) Yabancı çıtalı kutu konstrüksiyonda levha ve tutkal türünün diyagonal basınç ve çekme direncine etkileri. Pamukkale Üniversitesi Mühendislik Bilimleri Dergisi, 9:137-142.

Aslan E (2006) Kutu konstrüksiyonlu mobilyalarda minifiksli köşe birleştirmelerin moment taşıma performanslarının belirlenmesi, Gazi Üniversitesi Fen Bilimleri Enstitüsü Yüksek Lisans Tezi, Ankara.

Atar M (2007) PVAc tutkalında viskozite değişiminin bazı ağaç malzemelerde yapışma direncine etkileri. Gazi Üniversitesi Politeknik Dergisi, 10(1):85-91.

Atar M, Özcifci A, Altinok M, Celikel U (2009) Determination of diagonal compression and tension performances for case furniture corner joints constructed with wood biscuits. Materials and Design, 30:665-670.

Çağatay K (2011) Çerçeve konstrüksiyonlu mobilya birleştirmelerinde farklı tekniklerin mukavemet özelliklerinin karşılaştırılması. Gazi Üniversitesi Fen Bilimleri Enstitüsü Doktora Tezi, Ankara.
Çelikel Ü (2006) Ahşap bisküvi tipi yabancı çıtalı mobilya köşe birleştirmelerin direnç özellikleri. Gazi Üniversitesi Fen Bilimleri Enstitüsü Yüksek Lisans Tezi, Ankara.

Danacı E (2009) Ahşap esaslı levhalardan üretilmiş kutu mobilya L- tipi köşe birleştirmelerde birleştirme tekniğinin moment taşıma kapasitesine etkileri, Gazi Üniversitesi Fen Bilimleri Enstitüsü Yüksek Lisans Tezi, Ankara.

Demirel E (2008) Kutu tipi mobilya konstrüksiyonlarının köşe birleştirmelerinde kullanılan farklı birleştirme tutkal ve malzeme türlerinin birleştirme mukavemetine etkileri, Zonguldak Karaelmas Üniversitesi Fen Bilimleri Enstitüsü Yüksek Lisans Tezi, Bartın.

Dizel T, Uzun i (2007) Yonga levha ile birleştirilen kenar masifinin yapışma direncine kullanılan tutkalın etkisi. Artvin Çoruh Üniversitesi Orman Fakültesi Dergisi, 8(1):15-25.

Efe H (1994) Modern mobilya çerçeve konstrüksiyon tasarımında geleneksel ve alternatif bağlantı tekniklerinin mekanik davranış özellikleri. Karadeniz Teknik Üniversitesi Fen Bilimleri Enstitüsü Doktora Tezi, Trabzon.

Efe H, Kasal A (2000) Kutu konstrüksiyonlu sabit ve demonte mobilya köşe birleştirmelerde çekme direnci, Gazi Üniversitesi Endüstriyel Sanatlar Eğitim Fakültesi Dergisi, 8(8):61-74.

Efe H, İmirzi HÖ (2001) Çerçeve konstrüksiyonlu masif mobilya "T" birleştirmelerde çekme dirençleri karşılaştırmaları. Gazi Üniversitesi Politeknik Dergisi, 4(4):95-101.

Efe H, Kasal A, Gürleyen L (2002) Çeşitli tutkallarla yapıştırılmış kutu konstrüksiyonlu kavelalı köşe birleştirmelerin basınç direnci. Gazi Üniversitesi Endüstriyel Sanatlar Eğitim Fakültesi Dergisi, 10(10):39-56.

Efe H, Kasal A, Diler H (2006) Kutu konstrüksüyonlu mobilyada lambalı kinişli köşe birleştirmelerin eğilme moment dirençleri. Afyon Kocatepe Üniversitesi Fen ve Mühendislik Bilimleri Dergisi, 6(1); 111-124.

Ekrem D (2010) Ahşap ve plastik kavelalı kutu mobilya birleştirmelerinin mukavemet özellikleri. Gazi Üniversitesi Fen Bilimleri Enstitüsü Yüksek Lisans Tezi, Ankara.

Efe H, Deniz E, Kasal A, Kuşkun T (2012) Ahşap ve plastik kavelalı kutu mobilya birleştirmelerinin mukavemet özellikleri. Gazi Üniversitesi Pol. Dergisi, 15(3):151-159.

Efe H, Özen E, Danacı E, Kasal A, Demirci S (2014) L tipi mobilya köşe birleştirmelerde malzeme çeşidi ve birleştirme tekniğinin moment taşıma kapasitesine etkisi. Kastamonu Üniversitesi Orman Fakültesi Dergisi, 14(1); 15-23.

Englesson $T$ (1973) Summary of the investgations of several particleboards in the swedish forest products research laboratory. Unnumbered Publication, Swedish Forest Products Laboratory, 4449.

Hanson S, Ring C, Encantada M, Staving M, Zamora D, Guess T, Emerson J (1995) Testing of plate (biscuit) joinery and adhesive for aplicability in constructing architectural products. International SAMPE Technical Conference Proceedings, 27:125-134.

İmirzi HÖ (2008) Farklı yapım teknikleri ve değişik kalınlıklardaki levhalar ile üretilmiş kutu tipi mobilyaların mukavemet özellikleri, Gazi Üniversitesi Fen Bilimleri Enstitüsü Doktora Tezi, Ankara.

Karaman A, Yıldırım MN, Güven Ş, Yeşil H, (2017) Karaçam odunundan hazırlanan $L$ tipi ahşap bisküvili mobilya birleştirmelerinin 
diyagonal kuvveti taşıma kapasitelerinin belirlenmesi. II. International Academic Research Congress (INES) 18-21 Ekim 2017 sayfa:916, Alanya/Antalya

Kasal A, Diler H, Kocatürk i, Kasal Ö (2007) Kutu konstrüksüyonlu mobilyada L-tipi kavelalı köşe birleştirmelerin eğilme moment dirençleri. Afyon Kocatepe Üniversitesi Fen ve Mühendislik Bilimleri Dergisi, 7(2); 15-30.

Karaman A, Güven ş, Yeşil H, Yıldırım MN (2017) Farklı Tutkallar Kullanılarak Hazırlanan Mobilya Köşe Birleştirmelerinde Diyagonal Çekme ve Basınç Kuvvetinin Belirlenmesi, SDÜ Teknik Bilimler Dergisi, ISSN 2146-2119, Cilt no:7(2), Sayfa no:26-36.

Karaman A, Yıldırım MN, Güven Ş, Yeşil H (2017) Ahşap Bisküviler ile Polivinilasetat (Pvac-D4) ve Epoksi Tutkallar Kullanılarak Hazırlanan T-Tipi Mobilya Birleştirmelerinde Çekme ve Basma Kuvvetinin Belirlenmesi, 4. Uluslararası Mobilya ve Dekorasyon Kongresi,19-21 Ekim 2017, Düzce,Türkiye.'

Kirby IJ, Kelsey J (1996) Making joints, Rodale Press.

Rowell R (2005) Handbook of wood chemistry and wood composites. CRC Press, ISBN 0-8493-1588-3, New York.

Steiger R (2003) Fiber reinforced plastics (frp) in timber structures, Empa, 1-9.

Swamy RN, Jones R, Bloxham JW (1987) Structural behaviour of reinforced concrete beams strengthened by epoxy-bonded steel plates. Structural Engineer, 65:59-68.
Taljsten B, Blanksvard T (2007) Mineral-based bonding of carbon frp to strengthen concrete structures, Journal of Composites for Construction, 11(2):120-128.

Tüfekli Y (2010) Petek dolgulu levhalar ve farklı yapım teknikleri ile üretilmiş "L" tipi mobilya köşe birleştirmelerin moment taşıma kapasiteleri. Gazi Üniversitesi Fen Bilimleri Enstitüsü Yüksek Lisans Tezi, Ankara.

TS 64-3 EN 622-3. (2005) Lif levha özellikleri Bölüm 3: orta sert levhaların özellikleri, T.S.E, Ankara.

Türk M (2007) “Plastik ve ahşap esaslı kompozit bisküvilerle hazırlanan mobilya köşe birleştirmelerin bazı direnç özelliklerinin araştırılması. Zonguldak Karaelmas Üniversitesi Fen Bilimleri Enstitüsü Yüksek Lisans Tezi, Karabük.

Vassiliou V, Barboutis I (2006) Tension strength of furniture middle joints constructed with biscuits, In 10th Anniversary Conference of EngineRring Desing, Interior and Furniture Design. 17-18 October Sofia, Bulgaria.

Verbindugs T (2005) The lamello wood joinig system training course $\mathrm{CH}$ 4416. Lamello AG Bubendorf.

Yüce Y (2016) Ahşap kompozit levhalar ve bisküvi birleştirme tekniği ile üretilmiş mobilya köşe birleştirmelerinin direnç özellikleri. Gazi Üniversitesi Fen Bilimleri Enstitüsü Yüksek Lisans Tezi, Ankara.

Zhang JL, Erdil YZ, Eckelman CA (2002) Lateral holding strength of dowel joints constructed of plywood and oriented strandboard. Forest Product Journal, 52 (7/8):83-89. 